\title{
4
}

\section{Royal semantics: Linguacultural reflections on the Danish address pronoun De}

\author{
Carsten Levisen ${ }^{1}$
}

\section{Address studies}

Anna Wierzbicka's recent work on the cross-European semantics of address has reopened and invigorated 'address studies' (Wierzbicka 2015, 2016a, 2016b, 2016c). This is a remarkable achievement, given that the field of address for a long time has been considered 'old hat'-a wellstudied, almost trivial area of cross-European linguistics, from which very little innovation emerged. For decades, address was popular in both sociolinguistics and pragmatics. Typologies based on the so-called T-V pronouns (such as French tu/vous and German du/Sie) emerged out of sociolinguistic research, and in pragmatics the once flourishing paradigm of 'politeness theory' analysed address as a component of 'polite' verbal behaviour. Somewhere along the line, the interest in the meaning of address

1 I would like to acknowledge Anna Wierzbicka's profound influence and inspiration on my work, including the present work on the semantics of address. The first time I discussed address with Anna was in 2008 at the Australian Linguistics Institute. Drawing her attention to the special case of Danish address, Anna said: 'you should write about it!'. And so I did-with 10 years of delay. I would also like to thank Sophia Waters, Hartmut Haberland and the two anonymous reviewers of my chapter for engaging with my ideas, and helping me to improve on my analysis. 
was lost, and Wierzbicka's work allows us to reconsider this question: what do address words mean to speakers? In this chapter, I want to contribute to the meaning-based turn in address research following Wierzbicka's lead, and the emerging semantically driven address studies (see in particular Wierzbicka 2016a, 2016b, and the important contributions of Wong 2014: 57-93; Farese 2018).

A central part of Wierzbicka's (2016a) reopening of the field has to do with her search for a more fine-grained metalanguage as a tool for description. She says:

Simplistic distinctions such as that between 'familiar' and 'polite' forms of address, or between ' $T$ ' and ' $V$ ', are still widely relied on, and the focus of attention is often on collecting more data rather than on finding a framework within which the amassed data can be made sense of. (2016a: 523).

One has to agree with Wierzbicka that 'more data' cannot be the solution to the study of European address. We already know very well what the European address words are, and also great deal about how these words work in social interaction. The widest gap in our current knowledge is meaning, and Wierzbicka's 'meaning challenge' has consequences not only for address but also for 'relational grammars' in general - that is, the variety of ways in which different linguacultures construe the connection between the 'you' and the 'me' in conversational rituals.

Another key point in Wierzbicka's criticism (2016b) is the way in which comparative studies have been wedded to Anglocentric terminology:

conventional labels like 'informal', 'intimate', 'familiar', 'formal', and 'respectful', are all drawn from the conceptual vocabulary of English (2016b: 212)

A third problem identified by Wierzbicka (2016a) is the tendency to elevate the micro-diversity of usage above the macro-diversity of semantics, and to favour use over meaning. She says:

Yes, the use of terms of address changes over time and varies across the social spectrum, but differences in their use do not necessarily indicate differences in meaning (2016a: 506)

2 The study of relational grammars belongs the more general field of ethnosyntax (Wierzbicka 1979). 
I believe that all these points are important, and if I were to develop an analytical action plan based on these insights, I would propose the following:

Above all, we must insist on the retirement of the T-V system that was invented in the early '60s (Brown and Gilman 1960). While the T-V approach has taken us some distance, this simple system is too crude for meaning-based analysis, even if used critically and competently (see e.g. Braun 1988; Clyne et al. 2009; Hajek et al. 2013). The main problem is that $\mathrm{T}$ and $\mathrm{V}$ gloss over address diversity in European languages and lump together words and meanings based on superficial similarities, rather than on a deep meaning analysis. Moreover, $\mathrm{T}$ and $\mathrm{V}$ have also introduced a highly problematic dualistic thinking, as though there are only ever just two competing address terms, and as though the so-called 'Vs' are identical across Europe's languages. The dullness of analysis is partly due to the metalinguistic biases introduced by the T-V paradigm, and the solution is to adopt a metalanguage that allows for a more highresolution analysis, and which does not impose a simplistic duality like $\mathrm{T}$ and V. The Natural Semantic Metalanguage (NSM) offers itself as a metalinguistic tool for doing such analysis (Goddard and Wierzbicka 2014; Goddard 2018), and in my view, NSM analysis can fully replace the T-V system.

Second, the Anglocentric bias needs to be addressed head-on. By comparing Europe's languages through English words such as polite, formal, familiar, etc., we run the risk of viewing all these English words as neutral words, rather than value words with an Anglo cultural take on sociality and culture (for a criticism, see Wierzbicka 2010, on the problem of Anglocentrism, see also Levisen 2019; Ye 2019). Even if some of the traditional terminologies in address studies have quasi-counterparts in (some) European languages, there is a considerable 'cryptodiversity' at play in the terminology of values (Levisen and Jogie 2015). Precision in analysis cannot be reached unless we have a tertium comparationis, a common yardstick. This means that none of the explanatory keywords in English, not even solidarity or politeness, should be relied on when we analyse European address words and practices (on keywords, see also Levisen and Waters 2017).

Third, address words and practices are among the most important evidence for relational grammars in and across linguacultures. Address rituals play an important part in the everyday life of speakers. They model different 
ideas and ideals of kinship and family relations, patterns of friendship and colleagueship, and other kinds of social cognition that constitute social and relational knowledge. Address words are never just linguistic devices; they are always manifestations of cultural meaning. They are always 'linguacultural', and they profoundly link ways of speaking with ways of thinking about others (and ways of feeling towards other people). They deserve to be studied from a macro-diversity perspective, ${ }^{3}$ and from the perspective of cross-cultural semantics.

The chapter is structured as follows. In section 2, I will briefly introduce Danish linguaculture in relation to address words and practices. In section 3, I will present some 'rich points' on how De enables cultural discourse. In section 4, I will provide an explication for the Danish $D e$, and contrast and compare this with Wierzbicka's explication for German Sie. This is followed by some concluding remarks.

\section{2. 'Danish address' in the European context}

It seems clear that Danish address does not fit neatly into any of the two main camps of European address-neither the 'Anglo' nor the 'continental European'. The difference between 'Anglo' and 'Continental' can be summarised as follows:

One of the deepest differences between English-based human interaction and the interaction based on the languages of continental Europe has to do with terms of address. For speakers of languages like French, Italian, or German it goes without saying that 'polite' words such as vous, Lei and Sie are indispensable in daily exchanges with others. (Wierzbicka 2016b: 209)

At a first glance, Danish address seems to be both English-like and Continental-like. Anglo relational grammar is known for its extensive discourses of 'you', and in terms of cultural values, you has been called a 'great social equaliser' (Wierzbicka 2003: 47). The same can be said about the Danish $d u$. 'Du discourse' is linked with an egalitarian ethos, in much the same way as the Anglo inclusive 'you discourse'. But this is not

3 By macro-diversity, I refer to semantic differences in address words across different languages, and to intercultural analysis. By micro-diversity, I refer to differences in registers, genres, styles and dialects within the same linguaculture, and to intracultural analysis. 
the full story. After all, Danish does have an address word $D e$, which on the surface looks similar to German Sie, French vous, etc. An initial conclusion would be to say that discursive evidence points towards the 'Anglo' system, but that structural evidence points towards the 'Continental' systems.

Let's now take a closer look at De. Unlike the words Sie and vous that are ubiquitous in everyday German and French interaction, $D e$ is not a part of the daily exchange of words in Danish. The De, it would seem, has almost fallen out of use. To illustrate, I have myself, in my life as a Danish speaker, never used $D e$ in any 'normal' exchange of words. In fact, I have never used the word seriously at all—only for humorous or other rhetorical purposes. To the Danish mind, the 'fall of the $D e$ ' forms part of the narrative of a Danish egalitarian ethos that grew out of the popular enlightenment and social democracy, and which was consolidated through the anti-authoritarian and anti-hierarchy discourses of the 1960s (see Hansen 1980: 89; Levisen 2012). Even the conservative newspaper Jyllands Posten, whose renowned slogan used to be hvis De vil vide mere 'if De want to know more' has given up on $D e$. To avoid ridicule, the paper has recently changed its slogan to hvis du vil vide mere 'if you $[d u]$ want to know more'.

While the Danish De might be marginal in discourse, studies show that speakers are very much aware of the word (Kretzenbacher et al. 2018). De may have fallen, but the fall has mainly happened at the interactive level; the word is still alive and kicking in speakers' linguistic consciousness. The reason for this seems to be that $D e$ provides speakers with meaning potentials and indexical affordances. One of these indexical affordances is to create voices from the past: if you want to make, say, a historical Danish film, just insert $D e$ in the dialogue, and the Danes will be convinced that 'it feels old'. No other historically based lexicogrammatical and sociophonetic features of older stages of Danish seem to have same seductive power: $D e$ is recreating a sense of 'the old days' before the victory of social democracy, and the rise of an egalitarian ethos. Even the spelling of the word, with the old-fashioned capitalised D, contributes to invoking relational norms of the past.

In serious interaction, the Danish $D e$ is intricately linked with the Danish royal family. Almost akin to the 'royal registers' known from (for example) African linguistics (Storch 2011: 23-26), Danish 'De discourse' seems to have a royal ring. Using myself as an example again, the only situation in 
which I would feel obliged to use the word De seriously would be if I were to have a conversation with a member of the Danish royal family. This has not happened yet.

But claiming 'De discourse' as a royal-only register might be going too far. Perhaps it would be more apt to categorise $D e$ as a feature of 'residual conservatism', and with a royal prototype. There are pockets of $D e$ use and De users not only in the Danish royal court, but also in certain business cultures (such as Maersk), in certain connoisseur shops (such as Perch's tea shop), towards old elite-looking Copenhageners, but the fact of the matter is that for most speakers of Danish, $D e$ is a nice-to-have word, not a need-to-have word. And the reason why it is nice-to-have is that $D e$ can be used to humorously elevate people to a royal-like status, akin to saying Your Majesty! sarcastically in English. De, then, has something interesting to offer in terms of sarcasm, and humorous subversion, and the Danes are generally into sarcasm and humorous subversion (Goddard and Levisen forthcoming; Levisen 2018).

At a more general level, 'Danish address' stands out in a European context for its 'minimalism' and 'exceptionalism' (cf. Levisen 2017). It is 'minimalist' in the sense that address words in general seem marginal in Danish linguaculture, and it is 'exceptionalist' in the sense that the majority of the few existing address words are the stylistically marked choice. Several address words that exist in Danish are actively discouraged, and have been actively discouraged for decades. This is true for the Germanbased address words that index 'old style', words such as De, $H r$. and Fru, (cp. German Sie, Herr and Frau) as exemplified in (1) but also socially stigmatised address words such as ven 'friend', makker 'mate', and do '(jovial Jutlandic address variant of) $d u$ ', as in (2). The English translations fail to capture the stigma, but in Danish such words index marginalised social or socio-regional speech.

(1) Vil De vare så venlig?

'Would De be so kind?'

Om forladelse, $\mathrm{Hr}$. Mortensen

'I beg your pardon, Hr. Mortensen'

Tak, Fru Nielsen

'Thank you, Fru Nielsen' 
(2) Ved du hvad, ven?

'You know what, ven?'

Hva' så makker?

'What's up, makker'

Tak for hjalpen, do!

Thanks for the help, $d o$ !

Besides the 'old' and 'stigmatised' indexicalities, more recent influxes of English address words in slang registers such as boss, roomie, dude, cutie and pal have also found their way into Danish, where they index a 'global' street style, and often impart a humorous tone. So to recap, Danish address is marginal as such, and the address term $D e$ is likely to index something like 'old and noble' because of its royal-like meaning.

\section{The Queen, the Swiss, the train: Encounters with De}

To further explore the meaning of $D e$, I will now discuss three 'rich points' in order to come to a clearer understanding of what $D e$ means.

The first rich point goes back to my childhood in a Jutlandic town. As a 10 -year-old pupil, I remember having the first 'De awareness' moment in my life. Rumours had it that the Queen was coming to visit my town and that her procession would pass the town hall square where I happened to wait for the bus every day. Anxiously, I asked my mother what I should do if the Queen wanted to talk to me when she was passing the town square. I had heard in the schoolyard that I couldn't say $d u$ to her, and that there was another word De that was used to address royals. I had never heard about this word before and asked my mother if it was true. She said that it was highly unlikely that the Queen's visit would coincide with my bus ride. My mother was right, of course. The Queen's procession didn't pass during the 20 minutes that I happened to wait for my bus. Also, my mother reassured me that the Queen couldn't get mad at me if I forgot to say $D e$. Since I missed the Queen that day, I never got the chance to test my new word $D e$, and still to this day, this was the closest I ever got to using a serious $D e$ in my life. 
A second rich point in my life with De happened a couple of months ago, when I was travelling by train from Aarhus to Copenhagen. I was in a train carriage full of people, some standing, some sitting on the floor, and I was trying to write emails on my laptop in a very small personal space in the middle of a crowded car. There were elderly people who found it difficult to keep their balance as the train was rocking along, and it was truly uncomfortable for all of us. I decided to explore the train to see if there was better seating elsewhere, and to my surprise I found two completely empty carriages. This annoyed me. I was thinking of all the people in the other carriage, and I complained to the conductor. I asked her why she hadn't informed the passengers via the loudspeaker system that there were empty carriages when she knew that passengers were struggling in the overcrowded carriage. She responded that it wasn't her problem and that it was the passengers' own responsibility to find a place to sit. I disagreed with her publicly. Then she started addressing me with $D e$. For the rest of our slightly heated conversation, she called me both $H r$. and $D e$, which upset me further. It felt like she was saying 'mind your own business, Your Majesty'. I felt that she talked down to me in a passive-aggressive way, and that what she really communicated was that I had dared to think of myself as someone 'above her'. The $D e$, then, was clearly in the service of 'cutting me down', and also ridiculing me for my alleged hubris.

The third rich point happened a few years ago, when the Swiss-based multinational coffee chain Nespresso opened their business in the Jutlandic town of Aarhus. I went to the shop one day, and to my surprise I was greeted with a $D e$. As a matter of fact, all employees used the address pronoun De when interacting with their Danish customers, and this was so unusual for me that I decided to do fieldwork in the store for a while. I listened to the De-based conversations, and I soon found out that most customers were bewildered by the $D e$. In fact most customers were annoyed by it, and some even angry. I interviewed an employee about the $D e$ use, and I was told that they were simply following company policy. The 'Swiss logic' seemed to be that the German Sie or the French vous needed a counterpart in Danish, and since this counterpart existed in the form of $D e$, all employees had been instructed to use it. I was further told in the store that the $D e$ was meant to express høflighed 'politeness'. When I queried it further, the employee admitted that a large number of customers found it incredibly uhøfligt 'impolite'. A couple of months later, I returned to the store and the De had gone. I interviewed the employees again and they confirmed that the De policy had been reconsidered, and that they had found new ways of expressing hoflighed 'politeness' that were more in line with Danish customers' preferences. 


\section{The Danish De and the German Sie}

The German Sie serves as a historical model for the Danish De (see e.g. Kretzenbacher et al. 2018), and the same is true for other address terms that index 'old' style in contemporary Danish such as $\mathrm{Hr}$. (Herr), and Fru (Frau). In Denmark, German language is no longer an important model for the borrowing of words and concepts, and general knowledge of the German language is no longer strong among Danish speakers. But the German Sie is one of the German words 'known' by the Danes-and the German Sie is largely reinterpreted and misunderstood. The Danish stereotype of German conversation as 'hierarchical' and 'stiff' to the point of being 'comical' is to a large degree finding its symbolic rationale in the notion of 'address' ${ }^{4}$ - and with a basis in 'Sie-for-De' transference. Let us take a look at the German Sie, as explicated by Wierzbicka (2016b: 229):

\section{[A] The German Sie}

a. when I say this, I don't think about you like I can think about children at the same time, I don't think about you like I can think about some other people

b. I don't think about you like this: 'I know this someone well'

c. I think like this:

'people can know some good things about this someone,

like they can think some good things about many other people'

In Wierzbicka's analysis, German Sie differs in meaning from other European address pronouns such as the French vous, and the Italian Lei and Voi. The explication reflects these differences (for an extensive semantic analysis of the two Italian words Lei and Voi, see Farese 2018). One of the key elements in Sie is that 'people can know some good things about this someone, like they can think some good things about many other people'. This 'positive', and 'pro-social' meaning is not conveyed by the De. In fact, the Danish De seems quite far removed from Sie, vous, Lei and Voi, and based on my analysis so far, I will propose the following explication for $D e$ :

4 Ørsness (2016) provides an interesting case study on the De-Sie complex, by exploring address practices in the teaching of German in Denmark. He proposes that a cultural cognitive dissonance analysis can explain the complex. 


\section{[B] The Danish De (in its rare, serious sense)}
a. when I say this, I don't think about you like I can think about other people
b. I don't think about you like this: 'this someone is someone like me'
c. I think like this:

'people can know that this someone is above other people,

like a king [m] is above other people, like a queen [m] is above other people

First, the theme about adults and children, which is present in German Sie (component (a)) as well in vous, Lei and Voi, does not seem to be a part of the meaning of De. This reflects the fact that neither adult Danish, nor children's Danish, nor adult-children interactions in general have any age-based construal of address, and a shift from $d u$ to $D e$ does not seem to activate 'age' either. The main idea conveyed in $D e$ is 'specialness'- 'I don't think about you like I can think about other people', and 'difference''I don't think about you like this: "this someone is someone like me"'. Also, and importantly, the idea is to convey 'hierarchy' modelled on 'royalty'. I have used the two molecules king $[\mathrm{m}]$ and queen $[\mathrm{m}]$ - in Danish, konge 'king' and dronning 'queen'- to convey the royal prototype of the hierarchical cognition embedded in De. This final component should account for an 'aboveness of a royal-like kind'; that is, it should account for both the use in real interaction with royals (such as between journalists and the Queen), and the occasional shop in certain neighbourhoods in Copenhagen that uses De to enact a fornem 'posh, distinguished, noble' style.

The third component also provides us with a hook for explaining the humorous and sarcastic scripts associated with $D e$. With De one can mock another person's alleged special, outstanding and royal-like attitude or perceived status, and thereby police the cultural value of lighed 'equality, similarity'. For instance, the sarcastic De could be interpreted through a general Danish sarkasme script (see Goddard and Levisen forthcoming), but the master script that undergirds the aversion towards De discourse is a script against 'hierarchical social cognition': 


\section{[C] A high-level Danish script against 'hierarchical social cognition'}

many people think like this:

it is bad if someone thinks like this:

'I am not like other people, I am above other people'

it is good if someone can think like this:

'no one is above other people, no one is below other people'

The script in [C] spells out the socio-cognitive norm for thinking about good and bad thoughts in relation to being below and above others. The exception to script [C] is the Danish royal family. They are allowed to be 'above others', they can live by other scripts and follow other grammars of relationality. But even the royal family can go too far if they too demonstratively verbalise their exceptional status. In a much-discussed televised episode, Prince Joachim, the younger son of the Danish queen, once snapped at a journalist who failed to use De address, and insisted that the journalist changed his pronouns to fit the royal De code. The Danish public reacted very negatively towards the prince, and these reactions can be viewed as strong evidence in support for the cultural ethos reflected in script $[\mathrm{C}]$.

The script can also explain in part why Danish speakers, through a De-forSie transfer, largely misunderstand (or, to be more descriptive, reinterpret) the German Sie. The master script in [C] governs several lower-level scripts that remain to be articulated, including the scripts for 'royal registers', and scripts for humorous, sarcastic and subversive uses, and the indexical scripts for invoking 'old style', 'German style', and so on.

\section{Concluding remarks}

This chapter offered a first NSM-based analysis of Danish address, focusing on the Danish address pronoun $D e$. It was found that $D e$ is different from European words that have been compared to De, such as German Sie and French vous. It would seem that Danish linguaculture has its own cultural logics, based on Danish words and scripts, and that it is not just a copy of the German or the Anglo system. Close in spirit to the Anglo system of address, and close in form to Continental address culture, it seems that 
Danish, with its normalisation of 'zero address', with its focus on royal registers and humorous usages, constitutes a special case to the study of address that can help to explore the diverse ways in which Europeans do relational grammar in their daily lives. In order to study this diversity in depth, we need new approaches and new visions for address, and most of all we need to relinquish the strangleholds that prevent us from achieving this progress. I will conclude by sharing Wierzbicka's (2016a) vision, a vision that I also hold. It is a vision that can truly transform the study of address in Europe and the world:

we need to let go of technical terms (such as 'polite', 'familiar', 'distance', 'formality', and so on) and look for semantic components intelligible to native speakers and testable in context; and if we want to do so without ethnocentrism, we need to formulate our hypotheses (that is, the hypothesized semantic components) in cross-translatable words, put together into cross-translatable phrases and sentences (2016a: 523)

\section{References}

Braun, Friederike (1988). Terms of Address: Problems of Patterns and Usage in Various Languages and Cultures. Berlin: Mouton De Gruyter.

Brown, Roger and Albert Gilman (1960). The pronouns of power and solidarity. In T.A. Sebeok (ed.), Style in Language. Boston: MIT Press, 253-276.

Clyne, Michael, Catrin Norrby and Jane Warren (2009). Language and Human Relations. Cambridge: Cambridge University Press.

Farese, Gian Marco (2018). The Cultural Semantics of Address Practices: A Contrastive Study between English and Italian. Lanham, Maryland: Lexington Books.

Goddard, Cliff (2018). Ten Lectures on Natural Semantic Metalanguage: Exploring Language, Thought and Culture Using Simple, Translatable Words. Leiden: Brill.

Goddard, Cliff and Anna Wierzbicka (2014). Words and Meanings: Lexical Semantics Across Domains, Languages and Cultures. Oxford: Oxford University Press. doi.org/10.1093/acprof:oso/9780199668434.001.0001.

Goddard, Cliff and Carsten Levisen (forthcoming). The semantics of 'sarcasm' in Danish and English. 
Hajek, John, Heinz L. Kretzenbacher and Robert Lagerberg (2013). Towards a linguistic typology of address pronouns in Europe-past and present. Proceedings of the 2012 Conference of the Australian Linguistic Society, 1-15.

Hansen, Judith F. (1980). We are a Little Land: Cultural Assumptions in Danish Everyday Life. New York: Arno Press.

Kretzenbacher, Heinz L., John Hajek and Anne H. Fabricius (2018). 'Lånt men ikke kopiereret': The Danish $3 \mathrm{pl}$ address pronoun $D e$ as a historic calque from German Sie and its present use amongst Danish university students. Presentation at The fourth meeting of the International Network of Address Research, Helsinki University.

Levisen, Carsten (2012). Cultural Semantics and Social Cognition: A Case Study on the Danish Universe of Meaning. Berlin: Mouton de Gruyter. doi.org/10.1515/ 9783110294651.

Levisen, Carsten (2017). Danish-Communication Modes. In International Encyclopedia of Intercultural Communication. John Wiley \& Sons.

Levisen, Carsten (2018). Dark, but Danish: Ethnopragmatic perspectives on black humor. Special issue, 'Conversational humor: Forms, functions, and practices across cultures', ed. by Kerry Mullan and Christine Béal. Intercultural Pragmatics, 15 (4): 515-531. doi.org/10.1515/ip-2018-0018.

Levisen, Carsten (2019). Biases we live by: Anglocentrism in linguistics and cognitive sciences. Special issue, 'Biases in Linguistics', ed. by Simon Borchmann, Carsten Levisen and Britta Schneider. Language Sciences 76: 101173, doi.org/10.1016/j.langsci.2018.05.010.

Levisen, Carsten and Melissa Reshma Jogie (2015). The Trinidadian 'Theory of Mind': Personhood and postcolonial semantics. International Journal of Language and Culture 2(2): 169-93. doi.org/10.1075/ijolc.2.2.02lev.

Levisen, Carsten and Sophia Waters (eds) (2017). Cultural Keywords in Discourse. Amsterdam: John Benjamins.

Ørsness, Bjarne (2016). Forms of address as cross-cultural code-switching: The case of German and Danish in higher education, Linguistik Online 79 (5).

Storch, Anne (2011). Secret Manipulations: Language and Context in Africa. Oxford: Oxford University Press.

Wierzbicka, Anna (1979). Ethno-syntax and the philosophy of grammar. Studies in Language 3 (3): 313-83. doi.org/10.1075/sl.3.3.03wie. 
Wierzbicka, Anna (2003 [1991]). Cross-Cultural Pragmatics: The Semantics of Human Interaction (2nd edn). Berlin: Mouton de Gruyter.

Wierzbicka, Anna (2010). Experience, Evidence, and Sense: The Hidden Cultural Legacy of English. New York: Oxford University Press. doi.org/10.1093/ acprof:oso/9780195368000.001.0001.

Wierzbicka, Anna (2015). A whole cloud of culture condensed into a drop of semantics: The meaning of the German word Herr as a term of address. International Journal of Language and Culture 2 (1): 1-37. doi.org/10.1075/ ijolc.2.1.01wie.

Wierzbicka, Anna (2016a). Making sense of terms of address in European languages through the Natural Semantic Metalanguage (NSM). Intercultural Pragmatics 13 (4): 499-527.

Wierzbicka, Anna (2016b). Terms of address in European languages: A study in cross-linguistic semantics and pragmatics. In Keith Allan, Alessandro Capone, Istvan Kecskes and Jacob Mey (eds), Pragmemes and Theories of Language Use. Springer, 209-38. doi.org/10.1007/978-3-319-43491-9_12.

Wierzbicka, Anna (2016c). Terms of address as keys to culture and society: German Herr vs. Polish Pan. Acta Philologica 49: 29-44.

Wong, Jock Onn (2014). The Culture of Singapore English. Cambridge: Cambridge University Press.

Ye, Zhengdao (2019). The politeness bias and the society of strangers. Special issue, 'Biases in Linguistics', ed. by Simon Borchmann, Carsten Levisen and Britta Schneider. Language Sciences 76: 101183, doi.org/10.1016/j.langsci. 2018.06.009. 
This text is taken from Meaning, Life and Culture: In conversation with Anna Wierzbicka, edited by Helen Bromhead and Zhengdao Ye, published 2020 by ANU Press, The Australian National University,

Canberra, Australia.

doi.org/10.22459/MLC.2020.04 